\section{THREE-QUARTERS OF ADULTS BRUSH TWICE A DAY}

Just over a quarter of adults (26\%) say that cost affects their choice of dental treatment, according to the Adult Dental Health Survey. Almost a fifth (19\%) said that they have delayed dental treatment for the same reason.

The Executive Summary of the 2009 Adult Dental Health Survey shows that adults' dental health continues to improve over time and that while the large majority of adults who tried to get an NHS dental appointment in the three years prior to being interviewed successfully made and attended the appointment, accessing NHS dental services remained difficult for a small minority.

The findings show that, overall, 50\% of all adults with at least one natural tooth reported that they attended the dentist at least once every six months,
$21 \%$ indicated that they attended at least once a year, and a further $6 \%$ once every two years.

Almost two thirds (61\%) of dentate adults said the usual reason they attended the dentist is for a regular check-up. Ten percent said that they attended for an occasional check-up, while $27 \%$ said that they attended when having trouble with teeth. Two percent said that they never attended the dentist.

'Nearly four out of five adults (78\%) told us they had been given advice by a dentist or a member of the dental team on cleaning their teeth and gums,' said Ian 0'Sullivan from the Office for National Statistics, who carried out the survey. 'And three-quarters of adults surveyed cleaned their teeth at least twice a day.'

\section{NHS DENTAL PLACES CREATED FOR 6,000 IN HAMPSHIRE}

A new dental practice has opened in Totton, Hampshire that will provide 6,000 more people with much-needed NHS dentistry in the area.

With the new Totton centre in operation from 1 April this year, notfor-profit dental social enterprise SCA Trafalgar will be providing NHS dentistry to over 88,000 people in total in Hampshire. The Totton centre will also offer an enhanced service for children and will have a dental therapist available.

'We are very excited about the new service and have managed to recruit some highly trained and experienced staff to work with us,' said Sam Smith, Director of Trafalgar Dentistry.

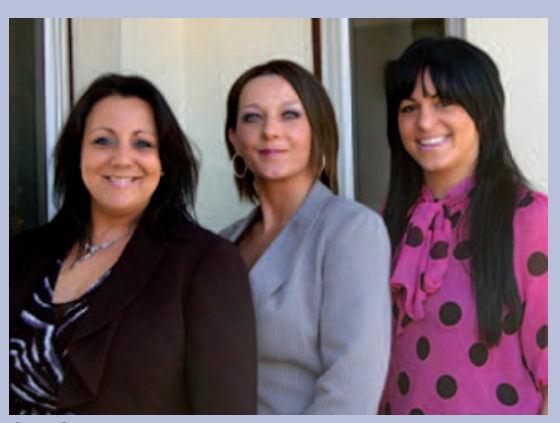

(L-R) Barbara Pearce, Dental Services Area Manager, Sam Smith, Director of Dentistry, and Stacey Ball, Manager of the new Totton practice

\section{DIARY}

\section{APRIL}

NADHAT/CDA Group -

Revalidation and the Salaried Services

Date: 11 April 2011

Venue: BDA, London

Email:CDS.Group@hotmail.co.uk

www.bda.org/events

BACD: Pink is the new white simple and predictable gingival surgery for the general dentist

Date: 13 April 2011

Venue: Liverpool

Email:suzy@bacd.com

Telephone: 02082418526

Get the Right Angle on Digital Imaging \& IRMER

Date: 13 April 2011

Venue: Leeds

Email: suzanne.o'rourke@henryschein.com

Telephone: 02920442818

2011 International Osteology Symposium Date: 14-16 April 2011

Venue: Cannes, France

Email:infouk@biohorizons.com

Telephone: 01344752560

www.biohorizons.com

iTOP: Developing proven strategies for more effective patient communication Date: 15-16 April 2011

Venue: Shrigley Hall, Macclesfield

Email:info@curaprox.co.uk

www.curaprox.co.uk

Posterior Restorations Made Easy

Date: 19 April 2011

Venue: Edinburgh

Email: enquiries@dentsply.com

Telephone: 01932837330

www.dentsplyacademy.com

\title{
BDA WELCOMES COC'S CLIMB-DOWN ON FEES
}

The BDA has said that the announcement of a dramatic reduction of the fees that many dental practices will pay for registration with the Care Quality Commission (CQC) is a major climb-down. Providers with up to three practices will pay significantly lower fees than were proposed in CQC's consultation, with the cost for those with a single location reduced from $£ 1,500$ to $£ 800$ and the cost for those with two or three locations reduced from $£ 3,000$ to $£ 1,600$.

Dr Susie Sanderson, Chair of the BDA's Executive Board, said: 'Dentists across England have made their concerns on this issue clear. Many have taken part in the BDA's red-tape campaign, articulating anxieties about the destructive effect costly, superfluous bureaucracy has on their working lives. These concerns appear, partially at least, to have been taken on board'.

\section{CLARIFICATION}

Following the report Endodontics awareness campaign launched in the news pages of the last issue (BDJ 2011; 210: 255) we would like to clarify that The Saving Teeth Awareness Campaign was organised and run by Julian Webber and Trevor Lamb of Harley Street Centre for Endodontics with support from other leading dental professionals. 